\title{
Microbial Safety of Milk from Vending Machines in the Informal Settlements of Nairobi, Kenya
}

\author{
Kevin W. Holi $\mathbb{D}$, Lucy G. Njue $\mathbb{i}$, and George O. Abong' \\ Department of Food Science Nutrition and Technology, University of Nairobi, P. O. Box 29053-00625 Kangemi, Nairobi, Kenya \\ Correspondence should be addressed to Kevin W. Holi; kevinholi45@gmail.com
}

Received 23 July 2021; Accepted 22 September 2021; Published 7 October 2021

Academic Editor: Shudong He

Copyright ( 92021 Kevin W. Holi et al. This is an open access article distributed under the Creative Commons Attribution License, which permits unrestricted use, distribution, and reproduction in any medium, provided the original work is properly cited.

\begin{abstract}
The microbial quality of milk is an important parameter in determining its safety. Processes such as pasteurization are meant to ensure milk is safe for consumption; however, postpasteurization activities could lead to milk contamination, hence threatening the health of consumers. This study sought to determine the microbial safety of milk obtained from vending machines that were located in Nairobi's informal settlements of Kibra and Dagoretti North. 37 milk samples were collected both from the storage tanks and vending machines located in the study area using a cross-sectional design and tested for microbial safety. Data were then recorded in datasheets and analyzed using frequencies and $t$-test with the aid of Statistical Package for Social Sciences software. Milk samples tested had acceptable levels of $\mathrm{pH}$ with a mean of 6.75 ; however, the $\mathrm{pH}$ of samples from the vending machines was lower than that of samples from the storage tanks. Milk samples from the vending machines had high levels of total viable count $(\log 4.7028 \mathrm{cfu} / \mathrm{mL})$ with $81 \%$ of the samples having counts beyond the acceptable standard. High levels of Staphylococcus aureus $(\log 2.5485 \mathrm{cfu} / \mathrm{mL})$ were also detected in $51 \%$ of the samples. Escherichia coli was detected in $27 \%$ of the milk samples from the vending machines, while Salmonella spp. was not detected. There was a significant increase in the number of total viable counts $(P \leq 0.001)$, Staphylococcus aureus $(P \leq 0.007)$, and Escherichia coli $(P \leq 0.015)$ in milk samples from the vending machines compared to samples from the storage tanks. Study findings show that milk from the vending machines in the selected informal settlements of Nairobi is highly contaminated and can pose a health risk to consumers if taken without any further heat treatment. Milk vending machine handlers should be trained on practices that safeguard the quality and safety of milk. Public awareness should also be created on the general safety of milk from vending machines to protect consumers from potential health risks resulting from drinking contaminated milk.
\end{abstract}

\section{Introduction}

The microbial quality of milk is an important parameter that is often used in determining the safety of milk [1]. Milk hazards are constantly used as the primary determinants of milk quality due to the potential level of threat that they pose to consumers if present in milk. Milk being a complex biological fluid is highly nutritious and hence offers a conducive growth environment for various microorganisms. Contamination of milk often takes place at three preconsumption points in the value chain: during production, when it is being transported, and at the retail stage [2]. Previous studies show that the quality and safety of pasteurized milk is highly compromised at the retail points [3]. A study on the suitability of milk for consumption found pathogenic microorganisms in milk that had been stored for retail [4], and another study evaluating the microbial quality of pasteurized milk found high total viable counts and coliform bacteria in pasteurized milk [5].

Microbes are the main contributors to food-borne diseases especially in developing countries [6], and their presence in milk, particularly pasteurized milk, threatens the health of consumers. Some of the common microbial contaminants of milk resulting from poor milk handling practices include coliforms, enteropathogenic E. coli, Staphylococcus aureus, Salmonella spp., Listeria monocytogenes, and Bacillus cereus, among others [7]. Coliforms are indicator microorganisms that could indicate potential contamination of milk by faecal matter. Escherichia coli is one of the pathogenic microbial contaminants resulting 
from faecal contamination, and its presence in milk could result in food poisoning when consumed. Staphylococcus aureus can also cause food poisoning. It is readily available in the environment, especially on surfaces, and poor milk handling practices may lead to contamination of milk by the microorganism. Salmonella spp. constitutes common milk contaminants that cause salmonellosis and could occur in milk due to postpasteurization contamination. Listeria monocytogenes is another serious milk and dairy product contaminant that causes listeriosis, and its presence in milk is usually a result of poor pasteurization process or postpasteurization contamination [8]. If present in milk, these pathogens present a public health concern considering that milk is highly consumed at all levels of the society.

The informal markets in Kenya play a major role in the milk retail sector with over $80 \%$ of the milk that reaches the local market being distributed through informal channels [9]. The increased demand for milk has led to the adoption and widespread usage of milk vending machines since they offer better storage of milk at the retail stage and provide flexibility of prices for consumers [10]. Milk vending machines are compact complex equipment made up of a canister that is located inside the machine for storing milk, an agitator, a cooling system, and a nozzle for dispensing the milk. The machine is power-efficient with some having an automatic washing system for keeping it clean and an electronic payment system that determines the volume of milk to be dispensed. The upsurge of milk vending machines in informal settlements of Nairobi raises concern on the safety of milk from the vending machines due to questionable handling practices by vendors considering that milk vendors' practices are critical in determining microbial safety of milk sold to consumers. While vending machines have increased the convenience of milk retailing, their handling could threaten the safety of the milk sold. A study on the microbial quality of milk from vending machines in Slovenia indicated that the majority of the milk from the vending machines did not fulfill the hygienic-technical requirements as per the European Union regulations [11].

This study sought to determine the microbial safety of milk from milk vending machines in Kibra and Dagoretti North informal settlements of Nairobi, Kenya.

\section{Materials and Methods}

2.1. Study Site. The study was carried out in the informal settlements of Nairobi County, Kenya. Nairobi serves as the capital city of Kenya and has 17 subcounties with a population of over 4 million people according to the 2019 census report [12]. The majority of these people are low-income earners who live in informal settlements distributed across these subcounties. Two subcounties were purposively selected for this study; these include Kibra and Dagoretti North. The areas were purposively chosen since they contain some of the largest informal settlements in the county with a high population density.

Figure 1 shows the locations of Kibra and Dagoretti North. Kibra is located to the southwest of the city of Nairobi, and it is approximately $12.1 \mathrm{~km}^{2}$ and has a population of around 178,000 people. Dagoretti North is located to the west of Nairobi city, and it is approximately $29 \mathrm{~km}^{2}$ with a population of around 181,000 people. These two regions have areas characterized by unplanned settlements, poor quality of housing, inadequate access to safe water and sanitation, and poor drainage systems among others.

2.2. Research Design. A cross-sectional design with an analytical component was used to conduct the study where data were collected at a given point in time from the study population. The analytical element entailed laboratory analysis of milk samples collected to determine the level of microbial contamination in milk from the vending machines. This design was appropriate for the study, since it made it possible to estimate the extent of microbial contamination in milk and also enabled the assessment of many outcomes within a reasonable time [13].

2.3. Study Setting. The informal settlements of Kibra and Dagoretti North represent the setting where the study was conducted. In Kibra, four wards were purposively selected for the study; these include Makina, Laini Saba, Lindi, and Sarang'ombe. In Dagoretti North, two wards were purposively selected; these include Kawangware and Gatina wards. These areas are characterized majorly by informal settlements and structures along which milk vending machines are stationed. The vending machines are randomly distributed in the areas without any specific order. Laboratory analysis of the samples was conducted at the University of Nairobi, Food Microbiology Laboratory.

2.4. Study Population. The study population comprised milk vendors and milk vending machines located in the informal settlements of Kibra and Dagoretti North. A previsit was carried out within the study setting to establish the total number of milk vending machines that are available and in operation in the area. The milk vending machines served as sampling units.

2.5. Sample Size. An exhaustive sampling of the available milk vending machines was carried out in the study areas according to the sampling frame illustrated in Figure 2. A total of 37 milk vending machines were identified, and 20 of them were from Dagoretti North, while 17 were from Kibra. All milk vending machines identified were included in the study. Milk samples $(250 \mathrm{ml}$ each) were collected in duplicate from the available milk vending machines for laboratory analysis.

2.6. Sampling Procedure. Sampling of milk from the vending machines for laboratory analysis was conducted within a period of two months in the months of August and September 2020, beginning with Dagoretti North and then Kibra. The selection of the months for sampling was not based on any factors. Sampling was done on the morning of each sampling date. Milk 


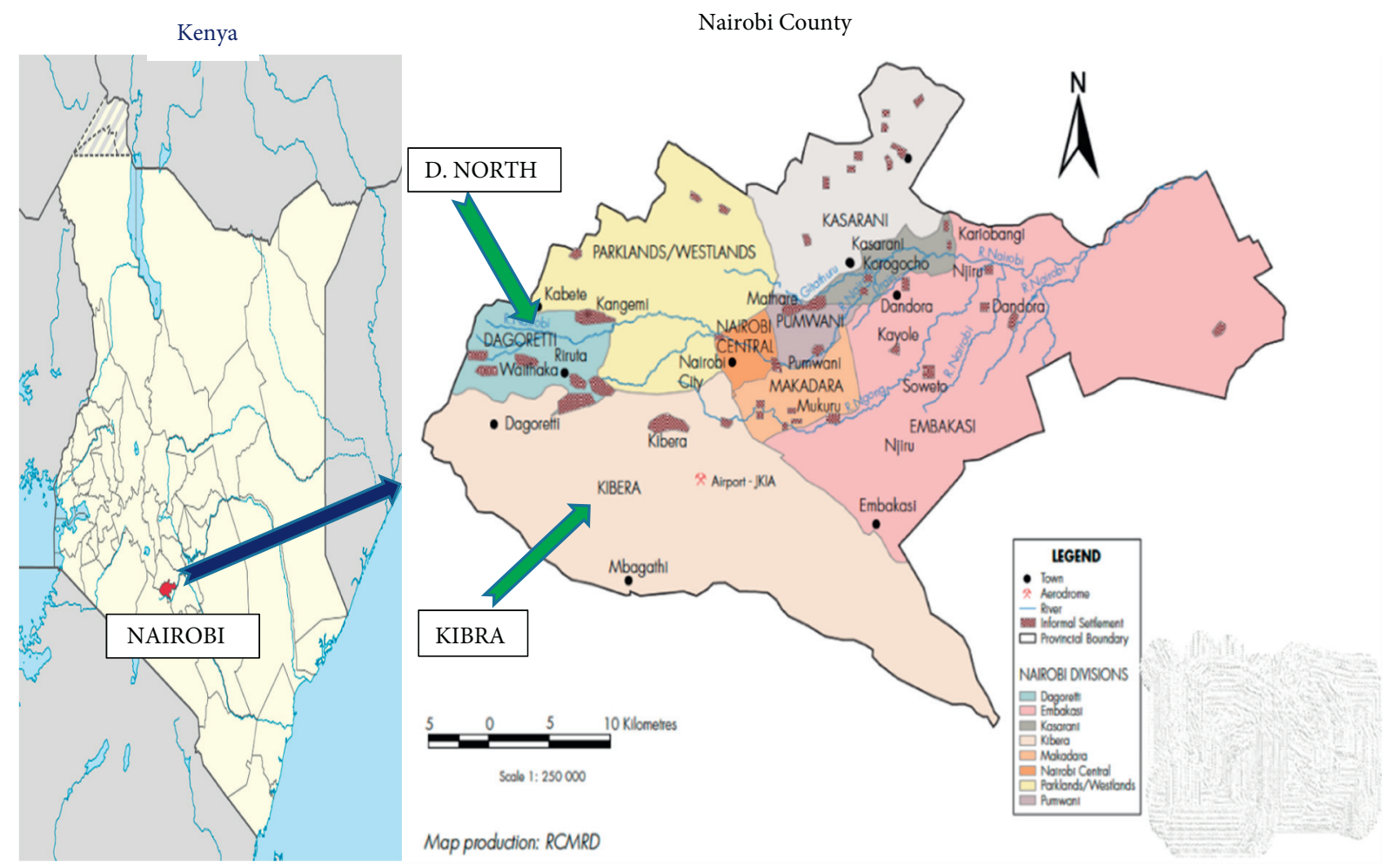

FIgURE 1: Location of Kibra and Dagoretti North from Nairobi County (RCMRD).

samples ( $250 \mathrm{ml}$ each) were collected from the canisters located inside the machines through the nozzles of the selected vending machines using sterile sampling bottles and according to ISO $707: 2010$ on milk sample collection. A similar amount was sampled from the storage tanks that had been kept alongside the vending machine with milk awaiting to be refilled into the vending machine canisters. Each sample was given a unique identification code representing a sample unit. The collected samples were then kept in insulated cooler boxes and transported to the laboratory within 2 hours after collection of the first sample for laboratory analysis.

2.7. Data Collection. Determining the microbial safety of milk from milk vending machines involved the collection of milk samples both from the delivery tanks and the vending machines and then taking them for laboratory analysis; the samples were analyzed within 24 hours of sampling. In the laboratory, milk samples collected were first tested for $\mathrm{pH}$ to determine their quality. The levels of microbial contamination in the milk samples were then analyzed, and results were recorded against the set regulatory standards for different microorganisms in order to determine the safety of milk from the vending machines.

Research tools used to collect the data include sampling bottles for collecting milk samples, labels for identification samples, a thermometer for measuring temperature, Marina $18 \mathrm{~s}$ cooler boxes for storage of milk samples during transportation, a refrigerator for storing samples in the laboratory, laboratory glassware for sample preparation, a Starter 2100-F OHAUS $\mathrm{pH}$ meter, Petri-dishes for inoculation of samples, a

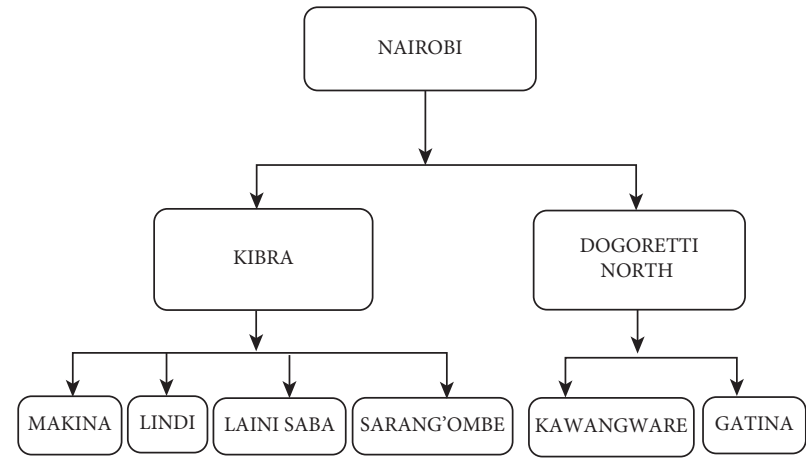

Figure 2: A flow diagram illustrating the sampling frame.

Memmert incubator model 100-800 for culturing microbes, an SC6PLUS colony counter for enumeration of colonies, and a SICCLCA-01 autoclave for sterilizing media and microbial cultures. Results from the laboratory tests were then recorded on a datasheet for analysis.

2.8. Ethical Consideration. This study was approved by the National Commission for Science, Technology and Innovation of Kenya under license number NACOSTI/P/20/ 5347.

2.9. Consent from Participants. Before sample collection at every sampling unit, respondents were informed that the samples collected were for research purposes and were asked to sign a consent form indicating the purpose and confidentiality of the data. 


\subsection{Analytical Methods}

2.10.1. Determination of Milk $p H$. Milk was first tested for $\mathrm{pH}$ upon arrival at the laboratory using a Starter 2100-F OHAUS pH meter made in the USA. For every milk sample, $20 \mathrm{ml}$ was obtained and transferred into a sterile beaker. The $\mathrm{pH}$ meter electrode was then rinsed with distilled water, wiped with a paper towel, and dipped into the $20 \mathrm{ml}$ milk sample. Milk $\mathrm{pH}$ reading as indicated on the $\mathrm{pH}$ meter was then taken and recorded in a datasheet before rinsing the electrode and returning it into its buffer. This was repeated twice for every milk sample tested.

2.10.2. Enumeration of Total Viable Counts. Milk samples were tested for the total viable count as per the KS ISO 48331 analysis method. Milk samples to be analyzed were prepared by transferring $10 \mathrm{ml}$ of a given sample into $90 \mathrm{ml}$ of a sterile diluent (Oxoid Buffered Peptone Water) and mixed thoroughly to form the primary dilution. Serial dilution was done by aseptically transferring $1 \mathrm{ml}$ of the primary dilution into another $9 \mathrm{ml}$ of sterile diluent using a sterile pipette. Further dilutions were prepared by transferring $1 \mathrm{ml}$ of each successive dilution into a further $9 \mathrm{ml}$ of diluent up to the fourth dilution.

Using a sterile pipette tip, $1 \mathrm{ml}$ of each chosen dilution was transferred into labeled sterile Petri-dishes starting with the most dilute solution of the dilutions prepared. Approximately $15 \mathrm{ml}$ of Oxoid standard plate count agar that had been tempered in a VWB- 6 water bath was then added aseptically to each inoculated Petri-dish. The contents of the Petri-dish were then mixed immediately after pouring by swirling the plates clockwise, anticlockwise, and sideways. After solidifying, the Petri-dishes were then incubated in an inverted position at a temperature of $30^{\circ} \mathrm{C}$ for 72 hours in a Memmert incubator made in Germany (Figure 3).

After 72 hours in the incubator, the standard plate count agar plates were removed and examined for the growth of colonies (total viable count) which was enumerated using a colony counter and expressed in terms of colony-forming units per milliliter $(\mathrm{cfu} / \mathrm{mL})$.

2.10.3. Enumeration of Staphylococcus aureus. Coagulase-positive Staphylococcus aureus was tested in the milk samples as per the KS ISO 6888-1 method of analysis. Milk samples were prepared by transferring $10 \mathrm{ml}$ of a given sample into $90 \mathrm{ml}$ of a sterile diluent (Oxoid Buffered Peptone Water) and mixed thoroughly to form the primary dilution. Serial dilution was done by aseptically transferring $1 \mathrm{ml}$ of the primary dilution into another $9 \mathrm{ml}$ of sterile diluent using a sterile pipette. Further dilutions were prepared by transferring $1 \mathrm{ml}$ of each successive dilution into a further $9 \mathrm{ml}$ of the diluent up to the third dilution.

Starting with the highest dilution to be plated, $0.1 \mathrm{ml}$ of a sample of each dilution suspension was aseptically transferred onto a pre-prepared Oxoid Baird Parker media plate. The inoculum was then spread over the surface of the agar plate using a sterile glass spreader, and the plates were left to dry. The inoculated plates were then inverted and incubated at $37^{\circ} \mathrm{C}$ for 48 hours.

Baird Parker plates were then removed and examined for the presence of black or grey shining colonies surrounded by a clear zone; this is the characteristic growth of typical coagulase-positive Staphylococcus aureus colonies on Baird Parker media. A confirmatory test was then carried out on the characteristic colonies through Gram staining where the presence of Gram-positive cocci strains appearing in clusters was confirmed. A coagulase test was also performed, and the colonies proved to be coagulase-positive Staphylococcus aureus.

2.10.4. Detection of Escherichia coli. Milk samples were tested for the presence of Escherichia coli using HiCrome chromogenic agar from HiMedia. Milk samples were prepared by transferring $10 \mathrm{ml}$ of a given sample into $90 \mathrm{ml}$ of a sterile diluent (Oxoid Buffered Peptone Water) and mixed thoroughly to form the primary dilution. Serial dilution was done by aseptically transferring $1 \mathrm{ml}$ of the primary dilution into another $9 \mathrm{ml}$ of sterile diluent using a sterile pipette. Further dilutions were prepared by transferring $1 \mathrm{ml}$ of each successive dilution into a further $9 \mathrm{ml}$ of the diluent up to the third dilution. Inoculation was then done by transferring $0.5 \mathrm{ml}$ of the sample dilutions onto the surface of the preprepared HiCrome chromogenic agar using a sterile pipette. The inoculum was then spread on the agar plate using a sterile glass spreader and left to dry. The inoculated plates were then inverted and incubated at $37^{\circ} \mathrm{C}$ for 24 hours and then examined for the presence of Escherichia coli.

After 24 hours in the incubator, blue/purple colonies on HiCrome chromogenic agar plates were selected as Escherichia coli characteristic colonies. The colonies were further confirmed to be Escherichia coli through an indole test by detecting the ability of Escherichia coli to break down the amino acid tryptophan to indole and form a red ring upon reacting with Kovac's reagent.

2.10.5. Detection of Salmonella spp. Detection of Salmonella spp. in the milk samples was done according to the KS ISO 6579-1 analysis method. Milk samples were prepared for analysis by transferring $25 \mathrm{ml}$ of a given sample into $225 \mathrm{ml}$ of a sterile diluent (Oxoid Buffered Peptone Water) and mixed thoroughly to form the preenrichment stage. The contents were then incubated at $37^{\circ} \mathrm{C}$ for 24 hours. The selective enrichment stage was then followed, where $0.1 \mathrm{ml}$ of the preenrichment culture was transferred to $10 \mathrm{ml}$ of Rappaport-Vassiliadis Soya Peptone Broth (RVS) from Oxoid and incubated at $41.5^{\circ} \mathrm{C}$ for 24 hours. This was followed by plating on a selective medium; a loop full of the selective enrichment broth was subcultured by streaking onto the surface of the pre-prepared Xylose Lysine Deoxycholate (XLD) agar plate from Oxoid and incubating at $37^{\circ} \mathrm{C}$ for 24 hours.

After 24 hours of incubation, Xylose Lysine Deoxycholate (XLD) agar plates were examined for the presence of colonies with a black center and a slightly transparent zone of a reddish color; this is the characteristic growth of 

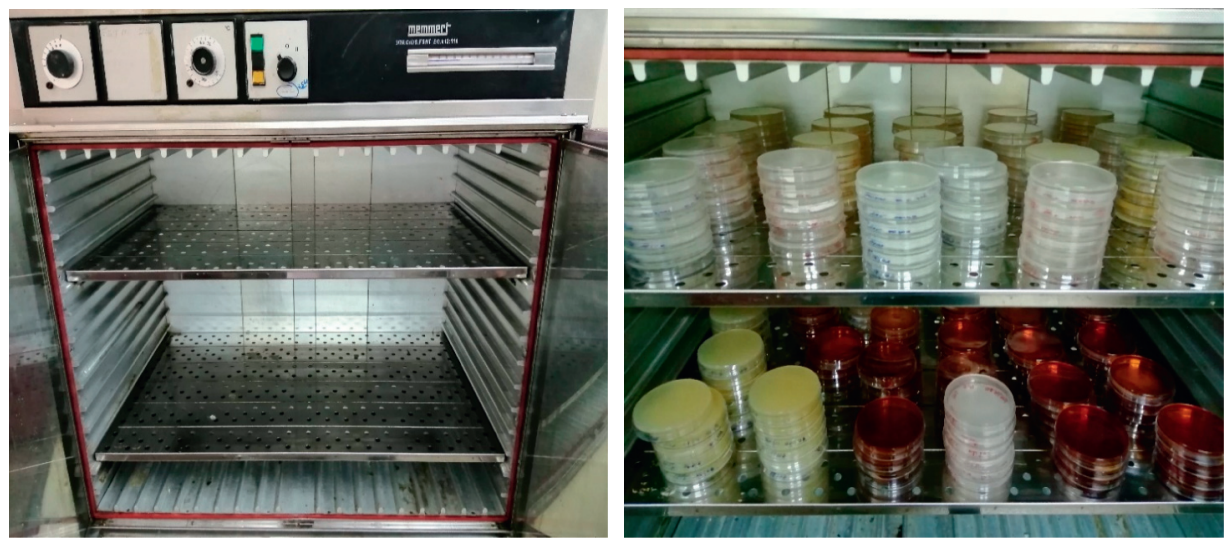

Figure 3: Plates incubated in a Memmert incubator for microbial growth.

Salmonella spp. on XLD agar. These colonies were further tested using biochemical tests to prove that they were Salmonella spp. by first purifying them through streaking the characteristic colonies on nutrient agar and incubating them at $37^{\circ} \mathrm{C}$ for 24 hours and then streaking the pure colonies on Triple Sugar Iron (TSI) agar and urea agar from Oxoid.

On TSI, Salmonella spp. produces an acid (yellow) butt and an alkaline (pink) slant, with blackening of the media due to production of hydrogen sulphide and cracks on the media as a result of gas production. On urea agar, Salmonella spp. is urease-negative and hence no color change is expected in urea agar for Salmonella spp. colonies; if the reaction is positive, urea is hydrolyzed, liberating ammonia and changing the color of the media to rose pink.

2.10.6. Data Analysis. Data on $\mathrm{pH}$ and microbial quality of milk from the vending machines were analyzed using Statistical Package for Social Sciences software (IBM SPSS v25). For microbial analysis of total viable count and Staphylococcus aureus, the number of colony-forming units per milliliter $(\mathrm{cfu} / \mathrm{mL})$ present in the samples was tabulated and recorded in datasheets and the data were analyzed. For Escherichia coli and Salmonella spp. tests, one point was given for every sample in which either of the microorganisms was present and zero points to samples where the two test microorganisms were absent. This is because Escherichia coli and Salmonella spp. are pathogenic microorganisms and only the detection of their presence or absence in milk was carried out. Data on milk pH and the amount of total viable count and Staphylococcus aureus in milk both from the storage tanks and from the vending machines were tallied, and their mean was calculated and then compared using a paired $t$-test. For Escherichia coli and Salmonella spp. tests, all the scores for the presence or absence of the microorganisms in the samples were tallied and summarized using frequencies and then calculated as a percentage. The level of statistical significance was set at $P<0.05$.

\section{Results}

3.1. Milk $p H$. Milk samples from the vending machines $(N=37)$ had an average $\mathrm{pH}$ of 6.83 , the highest having a $\mathrm{pH}$ of 7.02 and the lowest, 6.51. The average $\mathrm{pH}$ of samples from the storage tanks $(N=37)$ was 6.94 with the highest having a $\mathrm{pH}$ of 7.09 and the lowest, 6.65. The difference between the $\mathrm{pH}$ of milk samples from the storage tanks and the vending machines was highly significant $(P \leq 0.001)$. Figure 4 shows variation in mean, median, and range values for $\mathrm{pH}$ of the milk samples analyzed.

3.2. Total Viable Count. Figure 5 shows the growth of total viable count (TVC) colonies on standard plate count agar as isolated from milk samples in the study.

$92 \%$ of the milk samples picked from the vending machines $(N=37)$ had total viable counts with a mean of Log $4.7028 \mathrm{cfu} / \mathrm{mL}$. Of these samples, those from Dagoretti North had a mean total viable count of $\log 4.7155 \mathrm{cfu} / \mathrm{mL}$, with the ones from Kibra having a mean of $\log 4.6832 \mathrm{cfu} /$ $\mathrm{mL}$. For milk samples picked from the storage tanks $(N=37), 89.2 \%$ had total viable counts with a mean of $\log$ $4.4377 \mathrm{cfu} / \mathrm{mL}$. There was a significant difference $(P \leq 0.001)$ between the total viable counts of the samples from the storage tanks and those from the vending machines. Figure 6 shows variation in mean, median, and range values for TVC in the milk samples analyzed.

When tested against the current acceptable standards for total viable counts in pasteurized milk which is Log $4.4771 \mathrm{cfu} / \mathrm{mL}$ [14], $81 \%$ of the milk sampled from milk vending machines in this study had total viable counts above the recommended standard.

3.3. Staphylococcus aureus in Milk. Figure 7 shows the growth of coagulase-positive Staphylococcus aureus colonies on Baird Parker agar as isolated from milk samples in this study.

$51 \%$ of the samples from the vending machines $(N=37)$ were positive for coagulase-positive Staphylococcus aureus with a mean of $\log 2.5485 \mathrm{cfu} / \mathrm{mL}$. Of these samples, those from Dagoretti North had a mean of $\log 2.5832 \mathrm{cfu} / \mathrm{mL}$, while the ones from Kibra had a mean of $\log 2.5128 \mathrm{cfu} / \mathrm{mL}$ for coagulase-positive Staphylococcus aureus. For the milk samples picked from the storage tanks $(N=37), 41 \%$ of them were found to have coagulase-positive Staphylococcus aureus 


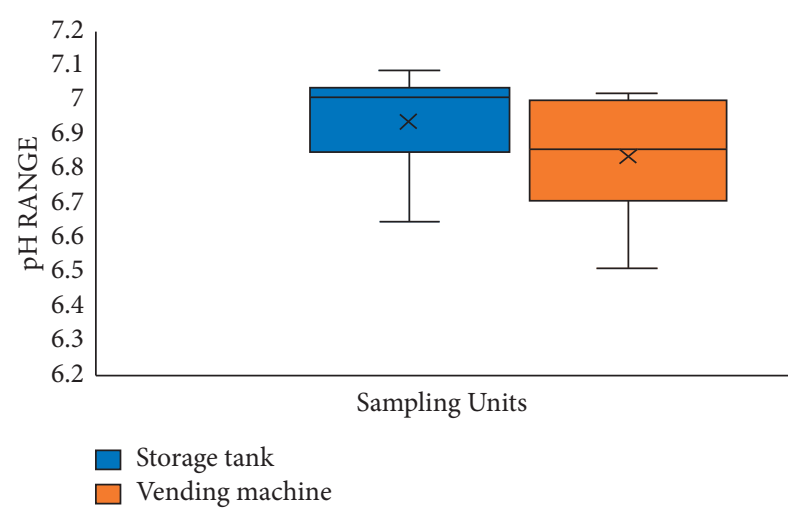

FIGURE 4: $\mathrm{pH}$ variation in milk from storage tanks and vending machines.

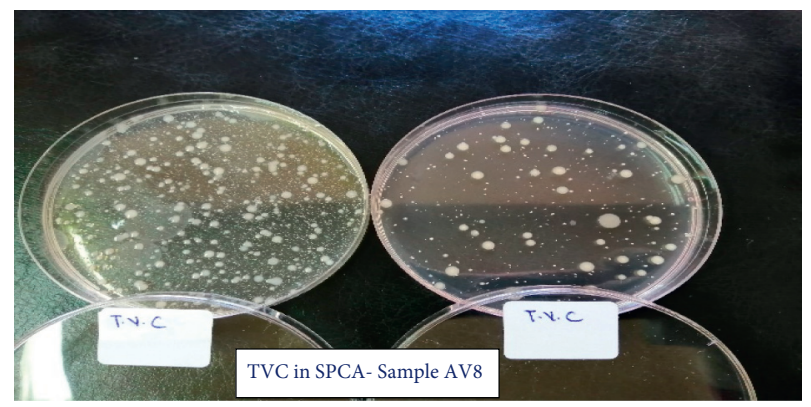

FIGURE 5: Total viable count colonies on standard plate count agar (SPCA).

with a mean of $\log 1.6483 \mathrm{cfu} / \mathrm{mL}$. There was a significant difference $(P \leq 0.007)$ between the amount of coagulasepositive Staphylococcus aureus in milk sampled from the storage tanks and those sampled from the vending machines. Figure 8 shows variation in mean, median, and range values for Staphylococcus aureus counts in the milk samples analyzed.

3.4. Escherichia coli in Milk. Figure 9 shows the growth of Escherichia coli colonies on HiCrome chromogenic agar as isolated from milk samples in the study and an indole positive reaction of the colonies.

$27 \%$ of the samples from the vending machines $(N=37)$ were positive for Escherichia coli. Of these samples, 25\% of those from Dagoretti North were positive, while in Kibra, $29 \%$ of the samples tested positive for Escherichia coli. For the milk samples picked from the storage tanks $(N=37)$, those positive for Escherichia coli were $8.1 \%$. There was a significant difference $(P \leq 0.015)$ between the number of Escherichia coli-positive samples from the storage tanks and those from the vending machines (Figure 10).

3.5. Salmonella spp. In Milk. Figure 11 shows the characteristic growth of Salmonella spp. colonies on Xylose Lysine Deoxycholate (XLD) agar and negative biochemical results for the Salmonella spp. colonies as tested on Triple Sugar Iron (TSI) agar and urea agar.

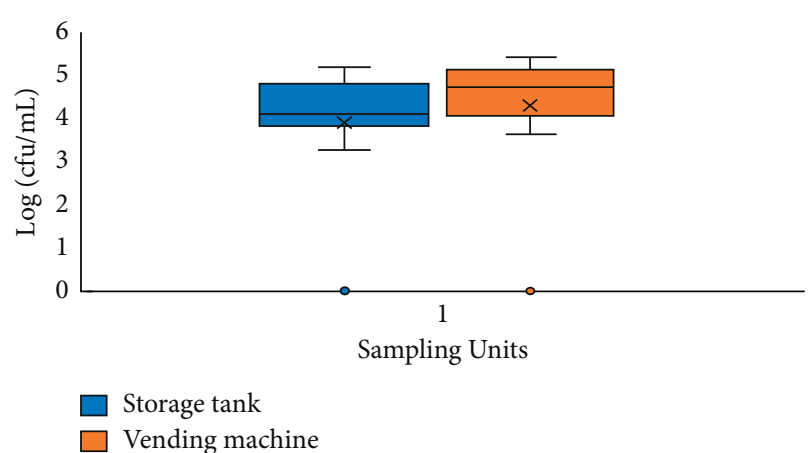

FIGURE 6: TVC variation in milk from storage tanks and vending machines.

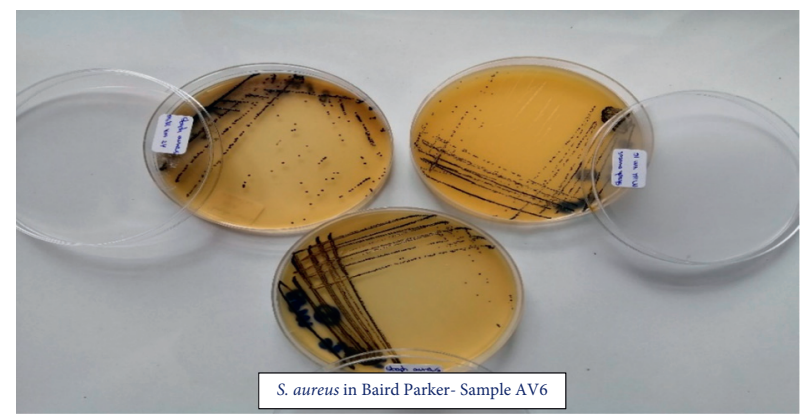

Figure 7: Staphylococcus aureus on Baird Parker media.

Milk samples analyzed in this study both from the vending machines and the storage tanks were negative for Salmonella spp. While some samples had colony growth on the selective media (XLD) that were characteristic for Salmonella spp., biochemical tests on TSI and urea agar confirmed that the colonies were not Salmonella spp.

\section{Discussion}

The average $\mathrm{pH}$ ranges for both milk samples from the storage tanks and the vending machines were within the acceptable range of pasteurized milk $\mathrm{pH}$ [14]. The significant decrease in milk $\mathrm{pH}$ in samples from the vending machines compared to those from the storage tanks shows an increase in microbial activity in milk due to the increased bacterial load in samples from the vending machines. The drop in $\mathrm{pH}$ results from microorganisms breaking down the milk constituents, leading to increased acidity as a result of the slow fermentation process as evident in similar studies [15].

An increase in the number of total viable counts in milk samples from the vending machines compared to samples from the storage tanks could be due to breaking of the cold chain during the storage of milk or poor hygiene practices in the handling of milk vending machines as evident in the study. Whenever milk handling equipment is not cleaned immediately or within 30 minutes after milk is removed, milk residues adhere on the milk contact surfaces and the adhesion and dryness of the residue increase with time making it difficult to adequately clean the machines, hence providing nutrients that support microbial growth in milk [16]. Storage conditions may also have contributed to an 


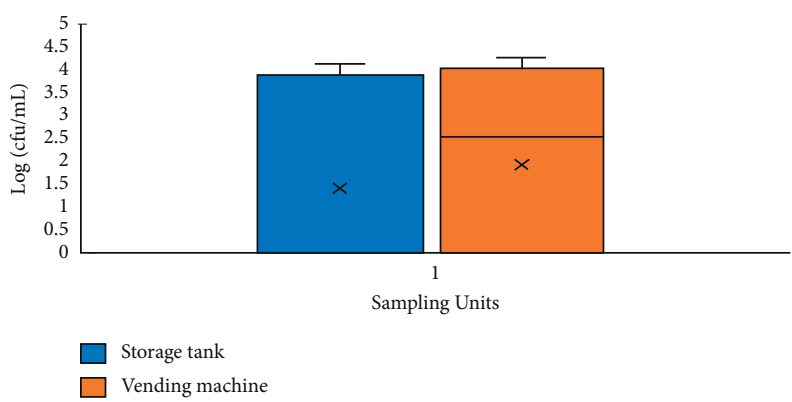

FIGURE 8: Variation of Staphylococcus aureus in milk from storage tanks and vending machines.
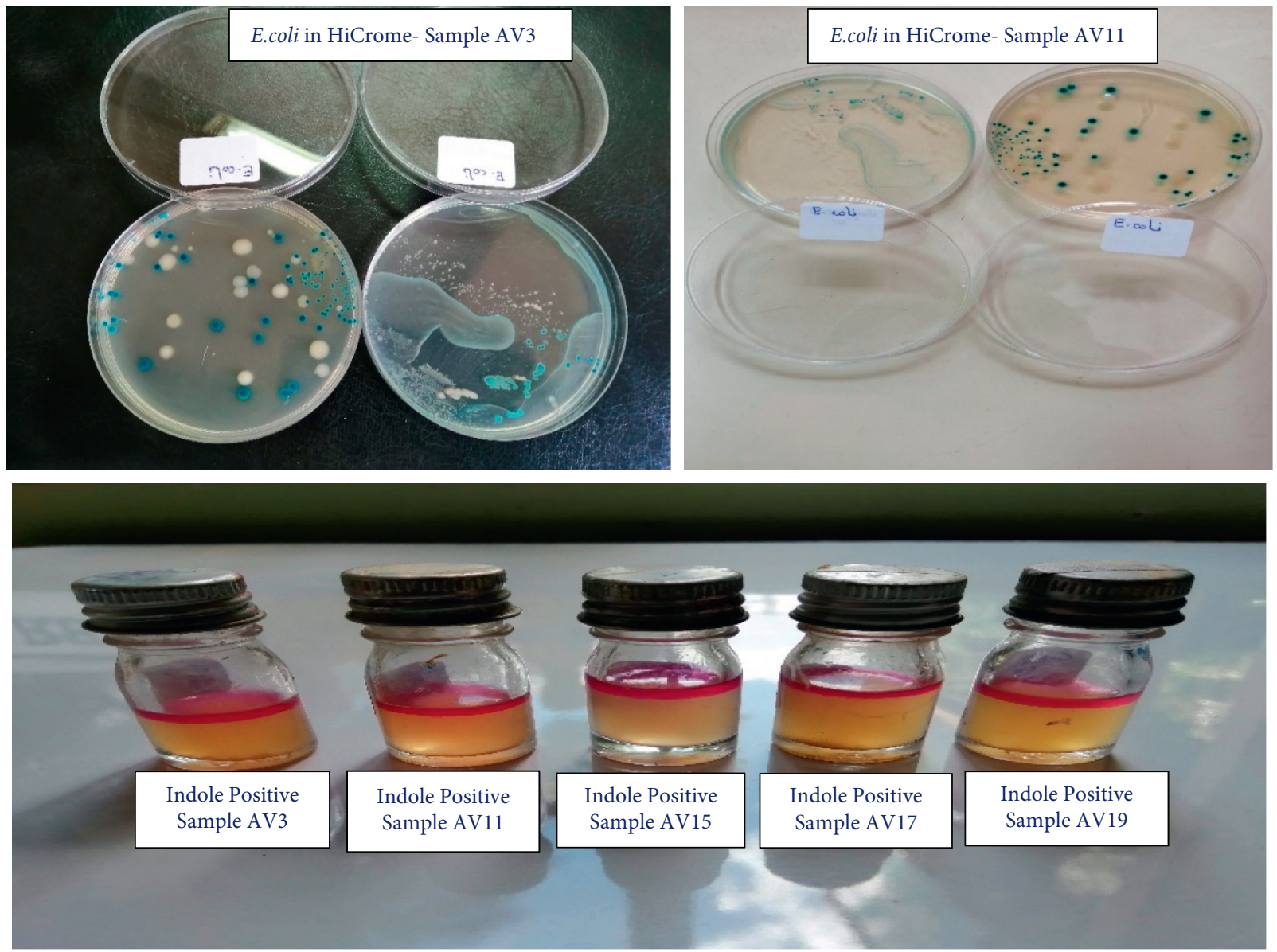

Figure 9: Escherichia coli on HiCrome chromogenic media and indole reaction.

increase in the number of total viable counts in milk from the vending machines; prolonged storage of milk in the vending machines within temperatures that favor microbial growth increases the number of total viable counts in milk [17]. A study by O'Connell et al. [18] established that the total bacterial content of milk stored at above $5^{\circ} \mathrm{C}$ increased with the duration of storage while the bacterial content of milk stored at between $2^{\circ} \mathrm{C}$ and $4^{\circ} \mathrm{C}$ did not increase as storage time increased.

The amount of total viable count in the milk samples from the vending machines differed significantly from the acceptable level in the regulatory standard confirming that $81 \%$ milk from the vending machines in this study is not fit for human consumption. A study by Wanjala [19] on the microbial quality of pasteurized milk found milk samples having a total viable count that exceeded $10^{6} \mathrm{cfu} / \mathrm{mL}$ and declared the quality of the milk unsatisfactory for consumption which is consistent with our finding. Another study evaluating the microbial quality of pasteurized milk in Bangladesh [5] found the milk to have high total viable counts, thus rendering the milk unsatisfactory for human consumption.

Staphylococcus aureus was detected in the milk samples both from the storage tanks and from the vending machines. There was a significant increase in the amount of Staphylococcus aureus in milk from the vending machines 


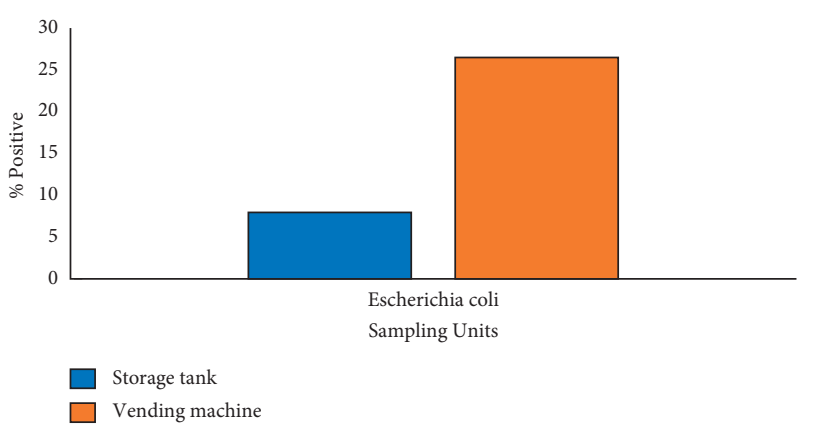

FIGURE 10: Escherichia coli variation in milk from storage tanks and vending machines.
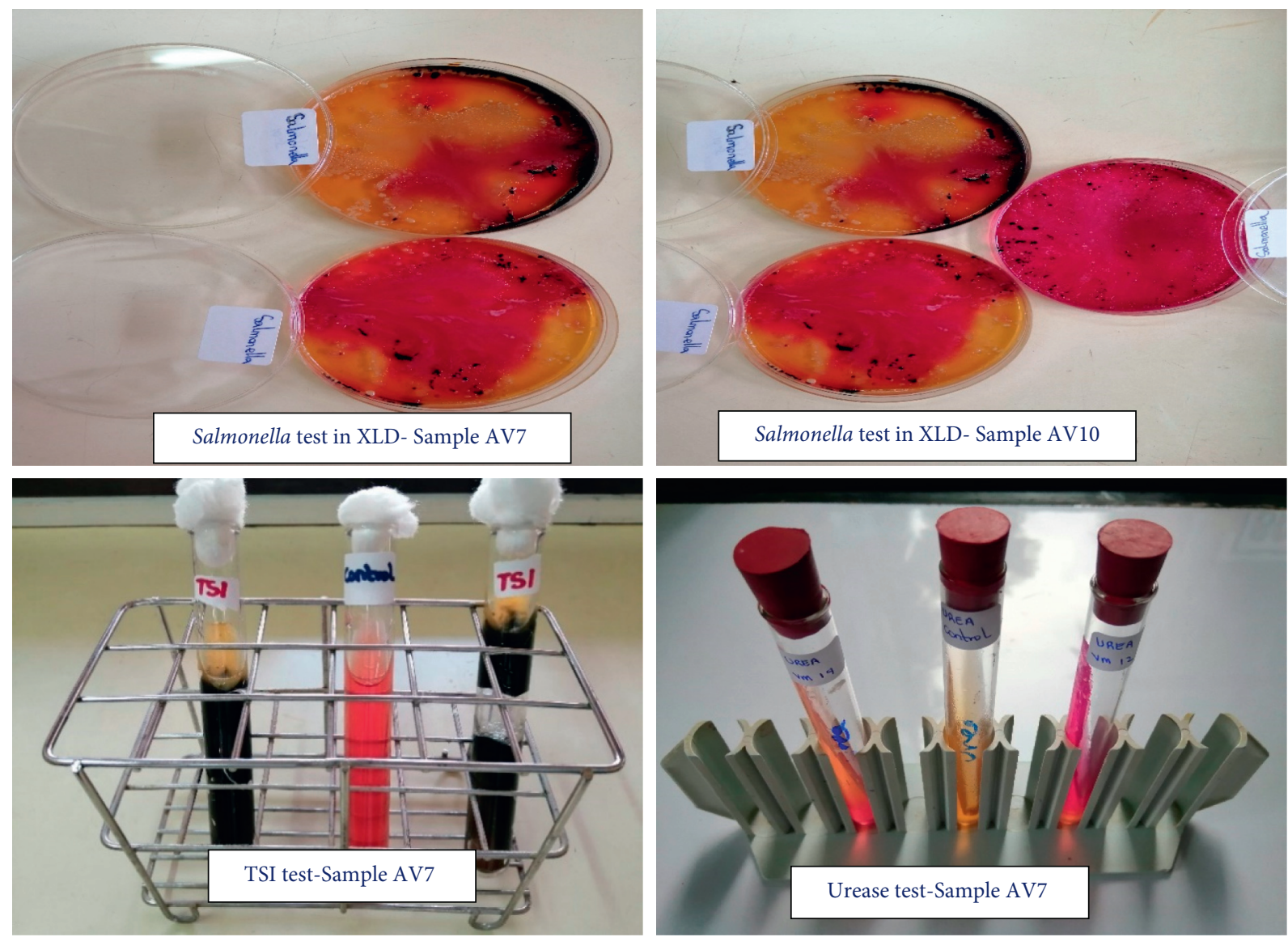

FIgURE 11: Characteristic colonies for Salmonella spp. on XLD agar and negative biochemical reactions on TSI and urea agar.

compared to that from the storage tanks. Staphylococcus aureus is an environmental contaminant that is commonly found on surfaces, and it may result from poor hygiene practices such as inappropriate cleaning of surfaces or using contaminated water for cleaning. When present in a given surface environment, Staphylococcus aureus forms biofilms that enhance its adherence to equipment surfaces, making it difficult to eliminate [20]. Poor cleaning and maintenance of the milk vending machines sustain the possible existence of Staphylococcus aureus on the equipment surfaces; the nutritious nature of milk together with favorable temperatures may be a contributing factor to the increase in the amount of Staphylococcus aureus in the milk samples from the vending machines. A similar study on screening of bacteria responsible for spoilage of milk confirmed the presence of Staphylococcus aureus in pasteurized milk [21]. Staphylococcus aureus is capable of producing heat-stable enterotoxins that can withstand heat treatment and is commonly responsible for food poisoning [22]. The amount of Staphylococcus aureus present in milk from the vending machines in this study threatens the health of consumers.

The presence of Escherichia coli in some of the milk samples from the vending machines is indicative of faecal contamination in milk or due to unhygienic handling practices [23]. An increase in the number of milk samples from the vending machines that are positive for Escherichia 
coli is a worrying sign of the hygienic state of the machines with the likely source of contamination being water that is used to clean the vending machines and the residual Escherichia coli being propagated by the breaking of the cold chain during storage of milk. While pasteurization of milk may help in eliminating pathogens like Escherichia coli, postpasteurization contamination is likely to occur as a result of poor handling practices. A study by Vahedi et al. [24] reported the presence of Escherichia coli in both raw and pasteurized milk and attributed this to contamination with wastewater and faecal materials. Another study on the microbial quality of milk from vending machines found Escherichia coli to be present in $33.3 \%$ of the samples [11]. Being a pathogenic microorganism, the presence of any amount of Escherichia coli milk renders the milk unfit for human consumption.

Salmonella spp. was not detected in the milk samples analyzed in this study, both from the storage tanks and the vending machines. These findings contrasted with those of similar studies where Salmonella spp. was found in pasteurized milk samples [25]. The characteristic growth colonies that turned out to be negative for Salmonella spp. after biochemical tests could be of other enteric bacteria that grow with similar morphological characteristics in the selective agar.

\section{Conclusion}

Milk from vending machines in the informal settlements of Nairobi is not fit for human consumption as indicated by the high level of total viable count, Staphylococcus aureus, and Escherichia coli contamination. Milk vending machines are a potential source of milk contamination as evident from the significant increase in the microbial load in milk after it has been stored in the machines, and they are therefore a safety concern that requires to be addressed urgently.

Vendor practices affect microbial safety of milk, and improving the practices of milk vending machine handlers through routine training and sensitization can help improve milk safety and reduce the health risks to consumers. The role of milk vending machines in the contamination of milk should be audited at a wider scale to understand the risk that these machines pose to the safety of milk. There is a need for public awareness on the microbial quality of milk from the vending machines through random sampling and testing by the regulator in order to protect the health of consumers.

\section{Data Availability}

The data used to support the findings of this study are available from the corresponding author upon request.

\section{Conflicts of Interest}

The authors declare that there are no conflicts of interest regarding the publication of this paper.

\section{Acknowledgments}

The authors gratefully acknowledge the University of Nairobi, Department of Food Science, Nutrition, and
Technology, for the provision of laboratory services and the competent technicians for their assistance. The authors also thank the milk vending machine handlers who took part in this study.

\section{References}

[1] A. S. Angelidis, S. Tsiota, A. Pexara, and A. Govaris, "The microbiological quality of pasteurized milk sold by automatic vending machines," Letters in Applied Microbiology, vol. 62, no. 6, pp. 472-479, 2016.

[2] M. Anderson, P. Hinds, S. Hurditt, P. Miller, D. McGrowder, and R. Alexander-Lindo, "The microbial content of unexpired pasteurized milk from selected supermarkets in a developing country," Asian Pacific Journal of Tropical Biomedicine, vol. 1, no. 3, pp. 205-211, 2011.

[3] S. Alonso, E. Muunda, S. Ahlberg, E. Blackmore, and D. Grace, "Beyond food safety: socio-economic effects of training informal dairy vendors in Kenya," Global Food Security, vol. 18, pp. 86-92, 2018.

[4] N. Mikulec, J. Špoljarić, Š. Zamberlin et al., "The investigation of suitability of raw milk consumption from vending machines in Croatia," Journal of Central European Agriculture, vol. 20, no. 4, pp. 1076-1088, 2019.

[5] B. Sourav Kumar, D. Kamal Kanta, and Md U, "Aftab Microbiological quality analysis of raw, pasteurized, UHT milk samples collected from different locations in Bangladesh," Stamford Journal of Microbiology, vol. 4, no. 1, pp. 5-8, 2014.

[6] A. H. Havelaar, A. Cawthorne, F. Angulo et al., "WHO initiative to estimate the global burden of foodborne diseases," The Lancet, vol. 381, p. S59, 2013.

[7] E. D. Van Asselt, H. J. Van Der Fels-Klerx, H. J. P. Marvin, H. Van Bokhorst-Van de Veen, and M. N. Groot, "Overview of food safety hazards in the European dairy supply chain," Comprehensive Reviews in Food Science and Food Safety, vol. 16, no. 1, pp. 59-75, 2016.

[8] S. Lee, L. Cappato, J. Guimarães et al., "Listeria monocytogenes in milk: occurrence and recent advances in methods for inactivation," Beverages, vol. 5, no. 1, p. 14, 2019.

[9] Odero and J. A. Waitituh, "Smallholder dairy production in Kenya; a review," Livestock Research for Rural Development, vol. 29, no. 139, 2017.

[10] H. Doležalová, K. Pícha, and J. Navrátil, “A bezemková factors that influence the selling of milk through milk vending machines," Acta Universitatis Agriculturae et Silviculturae Mendelianae Brunensis, vol. 62, no. 4, pp. 641-650, 2014.

[11] G. T. Karmen, K. Andrej, V. Stanka, B. Majda, G. An, and J. Mojca, "The microbiological quality of Slovenian raw milk from vending machines and their hygienic-technical conditions," Research Gate, vol. 119, no. 2, pp. 377-389, 2016.

[12] 2019 KNBS Kenya National Bureau of Statistics-Humanitarian Data Exchange.

[13] U. S. Kesmodel, "Cross-sectional studies-what are they good for?” Acta Obstetricia et Gynecologica Scandinavica, vol. 97, no. 4, pp. 388-393, 2018.

[14] 2016 KEBS Code of Hygienic Practice for Milk and Milk Products/KS 1552:2016-Full Catalogue Listing. http:// onlinecatalogue.kebs.org.

[15] S. Alonso, H. Varnell, R. Keefe, M. Wainaina, K. Roesel, and D. Grace, "Is my milk safe? quality and safety of the milk consumed in low-income households in Nairobi," 2018, https://cgspace.cgiar.org/handle/10568/98300.

[16] K. Godfrey, Milk Quality and On-Farm Factors Leading to Milk Spoilage in Bugaaki Sub County-Kyenjojo District, 
Makerere University Institutional Repository, Kampala, Uganda, 2013.

[17] L. F. Paludetti, K. Jordan, A. L. Kelly, and D. Gleeson, "Evaluating the effect of storage conditions on milk microbiological quality and composition," Irish Journal of Agricultural and Food Research, vol. 57, no. 1, pp. 52-62, 2018.

[18] A. O'Connell, P. L. Ruegg, K. Jordan, B. O'Brien, and D. Gleeson, "The effect of storage temperature and duration on the microbial quality of bulk tank milk," Journal of Dairy Science, vol. 99, no. 5, pp. 3367-3374, 2016.

[19] G. Wanjala, "Microbiological quality and safety of raw and pasteurized milk marketed in and around Nairobi region," African Journal of Food, Agriculture, Nutrition and Development, vol. 17, no. 1, pp. 11518-11532, 2017.

[20] C. Kong, C. F. Chee, K. Richter, N. Thomas, N. Abd Rahman, and S. Nathan, "Suppression of Staphylococcus aureus biofilm formation and virulence by a benzimidazole derivative, UMC162,” Scientific Reports, vol. 8, no. 1, pp. 2758-2816, 2018.

[21] V. Singh, S. Kaushal, A. Tyagi, and P. Sharma, "Screening of bacteria responsible for the spoilage of milk," Journal of Chemical and Pharmaceutical Research, vol. 3, no. 4, pp. 348-350, 2011.

[22] M. A. Shah, "Microbial analysis and quality control of milk collected from various districts of Khyber Pakhtunkhwa," International Journal of Pharmaceutical Research and BioSciences, vol. 2, no. 4, pp. 243-252, 2013.

[23] O. Samet-Bali, L. Roua, I. Felfoul, H. Attia, and M. Ayadi, "Detection of Escherichia coli in unpasteurized raw milk," International Journal of Agricultural and Food Science, vol. 3, no. 2, pp. 53-55, 2013.

[24] M. Vahedi, M. Nasrolahei, M. Sharif, and A. M. Mirabi, "Bacteriological study of raw and unexpired pasteurized cow's milk collected at the dairy farms and super markets in Sari city in 2011," Journal of Preventive Medicine and Hygiene, vol. 54, no. 2, pp. 120-123, 2013.

[25] A. S. Hasan, "Detection of salmonella spp. in milk samples of selected regions of Diyala city," Kufa Journal for Veterinary Medical Sciences, vol. 8, no. 1, 2017. 